\title{
ANNOTATION
}

\section{The Science and Art of Ophthalmology}

The death of Dr. A. S. Percival suggests some observations on the relations of pure science to the art or applied science of ophthalmology. He was facile princeps among British ophthalmologists in the mathematics of optics, and no one was keener than he in urging the importance of the study of these fundamental principles for accurate work with the ophthalmoscope and in the prescription of spectacles. Indeed, had it not been for the serious depreciation of American securities, he had intended to allot a considerable sum of money as an endowment for the teaching of optics to students of ophthalmology. While it is obvious that a knowledge of pure science is essential before it can be applied, it is not quite so obvious that a profound knowledge of first principles is necessary to the actual worker in the applied science. In the teaching of engineering, for example, at the present day few engineering students acquire any very deep knowledge of theory of differential and integral calculus, yet they become quite adept at using intelligently mathematical formulae, derived from the pure science, as efficient tools. The writer of this annotation once, in the enthusiasm of comparative youth, somewhat vigorously condemned his colleagues in the hearing of a distinguished physicist for their lack of interest in the theory of retinoscopy. The physicist's comment was-" "How many people who use a watch know really how it works?" One has to admit that it is perfectly true that retinoscopy can be used as a quite efficient tool by workers who have only a smattering of optics. Yet the fact remains that the worker who has thorough knowledge of the theory is a more efficient workman, especially in the more complicated cases with which he may at any moment be called upon to deal, than one who is not so equipped. The truth of this fact is inevitably borne in upon the minds of those who have had to teach students the use of the ophthalmoscope. It is not given to everyone to attain a thorough grasp of the "purer" sciences upon which his art is based, but few will deny that such knowledge makes a man a better worker, endows him with a pioneering spirit, and, not least, adds immeasurably to the interest and joy of his work. 